\title{
Local and Oral Antibiotics with Avoidance of Constipation (LOABAC) Treatment for Anal Fissure: a New Concept in Conservative Management
}

\author{
Pankaj Garg ${ }^{1,2}$
}

Received: 18 July 2015 / Accepted: 12 August 2015 /Published online: 14 October 2015

(C) Association of Surgeons of India 2015

Anal fissure is one of the most common presenting complaints in the outpatient departments of colorectal and general surgery. In spite of newer advances (nitroglycerin or diltiazem gels and botulinum injection locally) in the conservative management of this disease, up to $40 \%$ of patients would still require surgical intervention. In surgical options, lateral internal sphincterotomy (LIS) is considered as a gold standard by many surgeons because it is believed to be safe, has low morbidity, and is easy to perform. However, recent meta-analysis shows that LIS is associated with up to $14 \%$ incontinence rates. Therefore, the need for conservative management cannot be overemphasized.

As of today, chronic fissure-in-ano is considered a noninfective pathology and antibiotics have no role in its management. However, during the last decade, evidence is emerging to the contrary. In 2007, Pelta et al. found subcutaneous tract at the base of the fissure in almost all the patients and hypothesized sub-clinical infection as the reason for causing symptoms in chronic fissure-in-ano. In 2010, local application of povidine-iodine solution showed to improve symptoms in chronic fissure [1]. In 2012, it was demonstrated that a short course (5 days) of oral antibiotics (ciprofloxacin $500 \mathrm{mg}$ plus

The abstract of this manuscript was presented at - Annual meeting of American Society of Colon Rectum Surgeons (ASCRS) at Fort Lauderdale, Florida, USA on 21 May 2014

- Annual meeting of American Society of Colon Rectum Surgeons (ASCRS) at San Antonio, Texas, USA on 3 June 2012

Pankaj Garg

drgargpankaj@yahoo.com

1 Colorectal Surgeon, Indus Super Specialty Hospital, Mohali, Punjab, India

2 Garg Fistula Research Institute, 1042, Sector 15, Panchkula, Haryana, India ornidazole $500 \mathrm{mg}$ ) gave significant symptomatic relief in up to $90 \%$ patients [2]. However, this relief was not sustained if constipation was not strictly avoided. Subsequently, in 2014, it was shown that local application of antibiotics cream (ornidazole with or without povidine-iodine) for 3 months in addition to the above regimen (a short course of oral antibiotics plus avoidance of constipation, local application of Diltiazem gel was recommended if anal sphincter spasm was present) sustained the symptomatic benefits achieved and helped to cure the fissure in up to $90 \%$ of patients [3]. These findings are significant for two reasons. First, they highlight that infection can have an important role in etiopathogenesis of chronic fissure-in-ano. Secondly, high success rate of conservative management is encouraging, especially against the background of high complications of standard surgical treatment (LIS).

Therefore, local and oral antibiotics with avoidance of constipation (LOABAC) treatment shows a new direction in the management of chronic anal fissure. Prospective controlled preferably randomized studies would be needed to substantiate these results.

Conflict of Interest The author declares that he has no conflict of interest.

\section{References}

1. Durai R, Razvi A, Hin PN (2010) Novel use of povidone iodine in fissure-in-ano. Singapore Med J 51:837-8

2. Garg P, Lakhtaria P, Nalamati S, Gupta V, Thakur J (2012) Chronic anal fissure: is it an infection in a physically deformed lesion?-a new insight into an old plight. In Annual conference of American Society of Colon Rectum Surgeons (ASCRS). San Antonio

3. Garg P, Lakhtaria P (2014) Non-surgical management of chronic fissure-in-ano with high success rate: a simple novel concept in the treatment of chronic fissure-in-ano. In Annual conference of American Society of Colon Rectum Surgeons (ASCRS). Fort Laurderdale 